\title{
A Escola de Samba Bole-Bole em Belém/PA: história, comunidade e identidade
}

\section{The School of Samba Bole-Bole in Belém/PA: history, community and identity}

Margarida do Espirito Santo Cunha Gordo - Doutora em Educação pela Universidade Estadual de Campinas (UNICAMP). Pesquisadora de educação, educação não formal, carnaval e cultura popular, membro do Laboratório de Estudos sobre Arte, Corpo e Educação (LABORARTE), da UNICAMP. E-mail: margarida.gordo@ifpa.edu.br.

Herivelto Martins e Silva - Mestre em Comunicação, linguagem e cultura pela Universidade da Amazônia - UNAMA. É pesquisador de carnaval e cultura popular, músico, compositor, escritor e professor do Instituto Federal de Educação, Ciência e Tecnologia do Pará (IFPA). E-mail: heriveltosilva01@yahoo.com.br.

\section{Resumo}

Este artigo tem o objetivo fazer uma análise sobre a história do carnaval e de escolas de samba de Belém, a partir da Escola de Samba Bole-Bole, ressaltando a sua importância para a economia e o fortalecimento identitário de sua comunidade com o bairro a que pertence. Foi realizada uma revisão bibliográfica sobre o carnaval, tendo como referência a tese de doutorado de Gordo (2015). A relevância deste estudo se caracteriza em desvelar pontos significativos que acontecem nas escolas de samba, na maioria das vezes desconhecidos ou ignorados pela sociedade.

\begin{abstract}
This article aims to fly over the history of the carnival of samba school of Belém do Pará from the Bole-Bole Samba School, highlighting the importance of this samba school for the economy and identity strengthening of its community with The neighborhood to which it belongs. A bibliographical review on the carnival was carried out, having as reference the doctoral thesis of Gordo (2015). The relevance of this study is characterized in unveiling significant points that happen in samba schools, most often unknown or ignored by society.
\end{abstract}

\section{Palavras-chave}

Carnaval de Belém. Cadeia Produtiva. Comunidade. Identidade.

\section{Keywords}

Carnival in Belem. Productive Chain. Community. Identity. 


\section{INTRODUÇÃO}

Este artigo tem como objetivo fazer um sobrevoo sobre a história do carnaval de escola de samba de Belém do Pará a partir da Escola de Samba Bole-Bole, ressaltando a importância desta escola de samba para a economia e fortalecimento identitário de sua comunidade com o bairro a que pertence. Teve como base para sua construção a tese de doutorado de Gordo (2015).

A vivência no mundo carnavalesco na cidade de Belém há alguns anos, a carência de pesquisas e de material sobre este tema e a necessidade de trazer à luz as relações estabelecidas em uma escola de samba com o bairro a que pertence, foram o fio condutor para a realização deste estudo sobre o carnaval nessa cidade, dando ênfase ao movimento pelo qual passa uma escola de samba até que esteja pronta para o grande dia, que neste caso é o desfile oficial de carnaval promovido pela Fundação Cultural do Município de Belém (FUMBEL).

A Associação Carnavalesca Bole-Bole enraizada no populoso bairro do Guamá há 32 anos (fundada em 02.02.1984), mais especificamente na passagem Pedreirinha, será o objeto deste estudo. Apesar da pouca idade no que concerne às escolas mais antigas e tradicionais de Belém, a história da Bole-Bole se confunde com a história atual do carnaval paraense e já apresenta uma forte identidade e relação de pertencimento com sua comunidade, principalmente por possuir uma sede que serve de retaguarda, proporcionar atividades de emprego e renda e, por seu envolvimento com a cultura regional e popular paraense (DIAS JÚNIOR, 2009; FERREIRA, 2012).

A Bole-Bole, mesmo sem essa pretensão, substituiu a escola Arco-Íris em seu bairro. Iniciou desfilando em 1984 como bloco de carnaval, conquistando por mérito mudar de categoria para bloco de empolgação, ascendendo para bloco do grupo B e depois A. Em 1995 ascendeu para escola de samba do grupo B e em 1997 para o grupo especial. É a única escola de samba de Belém que passou por todas as categorias, desde bloco. Em seu histórico como escola de samba acumula quatro títulos de campeã (GORDO, 2015), inclusive o de Campeã do Carnaval dos 400 anos de Belém em 2016 e vários títulos de vice-campeã.

Quis o destino que a Bole-Bole fosse estabelecida na passagem Pedreirinha no bairro do Guamá. Esta pequena rua tem pouco mais de 500 metros de extensão e conta com uma grande diversidade de manifestações de cultura popular: boibumbá, bloco carnavalesco, terreiro centenário de umbanda, festa tradicional de São João, grupo de carimbó e outras. Por conta disso, essa escola de samba conta com a experiência desse povo em reunir-se para os festejos que acontecem o ano inteiro nessa rua e nesse bairro (FERREIRA, 2012). 
O texto foi estruturado com dois tópicos, Carnaval e escola de samba: que traça um breve histórico do carnaval no Brasil, fazendo um contraponto entre o carnaval de escola de samba do Rio de Janeiro com o de Belém do Pará. Afinal no que diz respeito à escola de samba, o Rio de Janeiro serve como inspiração e modelo para o país inteiro, apesar de no Brasil existirem muitos carnavais. Destaca também a cadeia produtiva que se desenvolve em torno do carnaval, bem como o mercado carnavalesco em Belém, trazendo demonstrativos financeiros da escola de samba Bole-Bole no ano de 2014.

Escola de samba: comunidade e identidade é o segundo tópico, que traz à luz o movimento da Escola de Samba Bole-Bole, abordando a importância de sua comunidade e a identidade que se estabelece nas vivências cotidianas, que são reforçadas pelos enredos e sambas-enredo cantados em cada carnaval.

\section{CARNAVAL E ESCOLA DE SAMBA}

Segundo Oliveira (2006), o carnaval no Pará, mais especificamente na capital Belém, teve seu início com o entrudo, manifestação festiva trazida pelos colonizadores portugueses para o Brasil no final do século XVII (1695), se estendendo até meados do século XIX (1844), ano marcado pela realização do primeiro baile de máscaras no Teatro Providência e a chegada de outras práticas carnavalescas no estado, como Zé Pereira, corso, clubes carnavalescos, carnaval de rua com sujos e mascarados, cordões etc., fase chamada de pós-entrudo. Aliás, este autor classifica o carnaval paraense em três fases: 1. Entrudo (1695-1844); 2. Pós-Entrudo (1844-1934) e 3. Carnaval da Era do Samba (a partir de 1934), subdividida pelo autor em duas fases: 1 . Carnaval das batalhas de confete que vai até 1957 e 2. Carnaval oficial de avenida, a partir de 1957.

Essas demarcações em fases não significam que houve uma nítida fronteira entre essas diversas manifestações carnavalescas, ou seja, não foi extinta uma fase para dar início a outra, segundo Gonçalves (2006) ao retratar esse movimento no Rio de Janeiro, essas manifestações atravessaram décadas, se inter-relacionando umas com as outras, até a total extinção de algumas dessas práticas.

Gonçalves (2006) apresenta uma classificação para essas manifestações carnavalescas que aconteciam no Rio de Janeiro no início do século XX: 1. Cordões - caracterizados por uma manifestação sem nenhuma organização, livre e muito barulhenta, constituída pela população pobre; 2. Grandes sociedades eram constituídas pela elite que se reunia nas associações e clubes, tinha como característica a organização e a pouca participação popular; 3. Ranchos - eram formados por grupos mais populares, em relação às grandes sociedades, sendo mais acessíveis, visto que 
posicionaram-se, como intermediários, entre os grupos "de elite" e os grupos "destituídos de educação e civilidade", produzindo um carnaval mediado por uma rede de relações sociais com lugar para os cronistas, os comerciantes, a polícia, os músicos, os artesãos, as tias baianas, além das camadas populares dos bairros e subúrbios (GONÇALVES, 2006, p. 74).

E mais

Os ranchos carnavalescos foram os primeiros grupos a se apresentar no carnaval com músicas próprias. Foram eles os primeiros a incluir o enredo, o cortejo linear e a formalizar uma estrutura de ensaios e desfiles que serviria, segundo alguns autores, de modelo para as escolas de samba (GONÇALVES, 2006, p. 76).

A ênfase dada aos ranchos deve-se a dois motivos, o primeiro é porque a forma de organização e de elementos que adquiriram, deu origem à escola de samba, foco deste estudo e, o segundo é pela forte influência que exerceram na origem de uma das mais antigas escolas de samba do Brasil e a primeira do estado do Pará, em um bairro da periferia de Belém, no Jurunas, o Rancho Não Posso Me Amofiná, que deu início ao movimento carnavalesco de escola de samba - apesar de muito incipiente em seus primeiros anos - evoluindo com o passar do tempo e adquirindo algumas características próprias, mas mantendo suas raízes ligadas ao carnaval carioca.

O carnaval carioca, na forma de desfile de escola de samba, foi oficializado pela Prefeitura do Rio de Janeiro em 1935, devido à repercussão positiva dos anos anteriores, em que eram promovidos pelos jornais. Tanto no Rio de Janeiro quanto em Belém, os jornais e as emissoras de rádio foram os grandes mediadores da institucionalização das escolas de samba e os promotores do carnaval de rua, das batalhas de confete, dos concursos de samba, do concurso de passistas - uma peculiaridade do carnaval de Belém (GALVÃO, 2009; OLIVEIRA, 2006).

A oficialização do desfile pela Prefeitura do Rio culminou em uma regulamentação, que suscitou certa organização, porém, tomou formas que foram "sufocando e desvirtuando a pureza da manifestação popular" (GALVÃO, 2009, p. 43). Sendo que o cumprimento às regras impostas pela prefeitura resultaria em ajuda financeira às escolas, do contrário deixaria as escolas sem esse auxílio. Assim, nenhuma dessas agremiações poderia se dar ao luxo de contrariar tal regulamentação. A institucionalização e a oficialização do carnaval vão de encontro ao entendimento de alguns autores

os espectadores não assistem ao carnaval, eles o vivem, uma vez que o carnaval pela sua própria natureza existe para todo o povo. Enquanto dura o carnaval, não se conhece outra vida senão a do carnaval. Impossível 
escapar a ela, pois o carnaval não tem nenhuma fronteira espacial. Durante a realização da festa só se pode viver de acordo com as suas leis, isto é, as leis da liberdade. O carnaval possui um caráter universal, é um estado peculiar do mundo: o seu renascimento e a sua renovação, dos quais participa cada indivíduo. Essa é a própria essência do carnaval, e os que participam dos festejos sentem-no intensamente (BAKHTIN, 1987, p. 6).

Turner (apud DAWSEY, 2005, p. 22) revela que "os carnavais surgem como momentos extraordinários, ou interrupções do cotidiano. No mundo do capitalismo industrial, eles surgem como interrupções do trabalho. São como momentos de "loucura" que se contrapõem ao cotidiano". Da Matta (1981) concebe o carnaval como uma festividade que estilhaça a realidade social, inventando uma ordem invertida, sem a existência de um centro de gravidade. Turner (2005), Bakhtin (1987) e Da Matta (1981) referem-se ao carnaval como uma quebra do cotidiano em busca de liberdade, mesmo que momentânea, do indivíduo, da pessoa e do ser humano. Com a institucionalização do carnaval e a implementação de regulamentos essa liberdade passou a sofrer ameaças.

É importante ressaltar que a oficialização do carnaval no Brasil se deu em plena ditadura varguista e, um dos itens do regulamento que precisava ser cumprido era o tema nacionalista. Este não partiu diretamente do governo, mas sim da União das Escolas de Samba que vislumbravam com isso a aceitação do governo, que usava os enredos nacionalistas das escolas como uma forma de propaganda positiva (GALVÃO, 2009).

É a partir da oficialização, que uma grande teia foi-se tecendo em prol do carnaval carioca. O espetáculo, que hoje deslumbra, também teve seus momentos de dificuldade. Porém, quando governo estadual e municipal, empresários e mídia perceberam o filão que seria investir no carnaval carioca, este deslanchou. Em torno do carnaval carioca há uma cadeia econômica muito bem constituída e articulada com os comandantes das escolas de samba e destes com a comunidade, que também envolve a contravenção do jogo do bicho.

No que concerne ao desfile de carnaval em Belém, segundo Oliveira (2006) e Palheta e Rodrigues (2010) este viveu seu apogeu na década de 1980, sendo considerado o terceiro maior e melhor carnaval do Brasil. Esse auge vivido pelo carnaval paraense se deu, principalmente por conta da fundação em 1983 da Escola de Samba Arco-Íris no bairro do Guamá, que apoiada pela mídia e por empresários locais, reproduziu o Carnaval do Rio de Janeiro na Doca de Souza Franco - antiga passarela do samba de Belém - ao trazerem como carnavalescos, os famosos Joãosinho Trinta e Laíla, comandantes artísticos da escola carioca Beija-Flor de Nilópolis, para liderarem a equipe de artistas que a referida ArcoÍris estava construindo. 
Pelo que foi capturado em pesquisas nos jornais da época, como "O Estado do Pará", que tinha um caderno especial sobre carnaval e em Oliveira (2006), em relação às escolas de samba, esse apogeu do carnaval foi muito pontual, pois a maioria das escolas, como exemplo a Quem São Eles, do bairro do Umarizal, vivia uma grande crise financeira, haja vista que seu presidente no ano de 1983 teve que vender alguns bens pessoais para pagamento de dívidas da escola e, encontrou como saída o arrendamento da sede por um empresário numa tentativa de que sua escola desfilasse no carnaval de 1983. Isso não aconteceu, sua escola não foi para a avenida.

Fato este que se repetiu no Rancho Não Posso me Amofiná. A escola de samba do bairro do Jurunas estava se reerguendo com a ajuda do empresário do jogo do bicho e político João Bosco Moisés - responsável pela construção de sua atual sede - e também sempre contou com o apoio da imprensa e da classe política e empresarial, devido principalmente à apelação de ser a primeira escola de samba de Belém e uma das mais antigas do Brasil, nesse ano de 1983 também não desfilou.

Já a escola de samba Embaixada do Império Pedreirense, também vivia uma série de dificuldades financeiras e estruturais, mesmo assim desfilou no carnaval de 1983 e acabou conquistando o terceiro lugar (OLIVEIRA, 2006). Outra escola de samba que entrou nesse cenário no início da década de 1980 e que era apoiada por um bicheiro, o sr. Waldir Fiock, foi a escola Acadêmicos da Pedreira, que teve alguns momentos de glória até a saída desse seu principal apoiador na década de 2000, ocasião em que esta foi enfraquecendo e atualmente não mais desfila. Naquele carnaval de 1983 a Acadêmicos da Pedreira foi a vicecampeã (OLIVEIRA, 2006).

A escola Arco-Íris do bairro do Guamá, também apoiada por um bicheiro, ex-senador da República Mário Couto Filho ${ }^{1}$, recém-fundada em 1983, estava com todo fôlego, inclusive financeiro, levando para a avenida do samba da época, a Doca de Souza Franco, os melhores sambistas de Belém e nomes consagrados do carnaval carioca (OLIVEIRA, 2006). Nesse ano o samba-enredo Um grande Coração Chamado Brasil de autoria do compositor Vetinho, um dos fundadores da Arco-Íris, se tornou o samba mais tocado e o que mais vendeu exemplares em toda a história do carnaval paraense com 54 mil cópias vendidas, segundo foi divulgado pela imprensa na época.

\footnotetext{
Mário Couto foi proprietário na década de 1980 da banca de jogo do bicho "A Favorita", chegando a ser um dos diretores da Associação dos Banqueiros e Bicheiros do Estado do Pará. Segundo entrevista ao jornal "Folha de São Paulo", Mário Couto admitiu que atuou na contravenção e, que seu envolvimento com o jogo foi em função de uma escola de samba chamada Arco-Iris, tendo sido chamado para organizar uma banca em troca de ajuda para a escola" (DIÁRIO DO PARÁ, 2013).
} 
O luxo e a grandiosidade, que foram a grande marca da escola Arco-Íris, aqueceram o mercado carnavalesco em Belém na década de 1980. É interessante observar que em 1983, ano de nascimento dessa escola e já se sagrando campeã, os sambistas cariocas, devido às dificuldades financeiras que enfrentavam, pediam ajuda aos governos municipal e estadual para que pudessem colocar suas escolas na rua para desfilar.

Em 1984 foi inaugurado o sambódromo do Rio de Janeiro na Marquês de Sapucaí, e foi criada a Liga Independente das Escolas de Samba (LIESA) que passou a administrar o espetáculo como um negócio. Assim, com a venda de ingressos, dos CD com os sambas-enredo das escolas, a negociação dos direitos de transmissão do desfile, foi-se formatando, com o passar dos anos, um modelo de carnaval autossustentável que teve como resultado um crescimento indescritível (MARQUEIRO, 2011).

Belém não acompanhou esse crescimento do carnaval carioca. A partir da década de 1990, com o fim da escola Arco-Íris, o carnaval paraense começou a perder força. Poderia ter aproveitado a explosão que foi a Arco Íris e todo o contexto empresarial e midiático que se desenvolveu na década de 1980, mas isso não aconteceu. Mesmo com muitas dificuldades, as escolas de samba resistem com o apoio de sua comunidade e conseguem se aprontar para o dia do desfile oficial.

Esse aprontar está intimamente relacionado com o capital de giro de uma escola de samba, que tem como principal fonte o incentivo financeiro proveniente da Prefeitura e do Governo do Estado, que além de ser insuficiente, quase sempre é disponibilizado às vésperas do desfile e às vezes até após o desfile. As escolas arrecadam muito pouco em suas quadras durante o ano. No que concerne ao carnaval, a indústria fonográfica é inexistente. A mídia descrente. Poder público e privado quase ausentes. As escolas longe de se tornarem uma unidade para lutarem com mais eficiência por melhorias para o carnaval, buscam isoladamente apoio financeiro para suprirem suas demandas.

A característica marcante dessa atividade cultural realizada em quase todo o país, é que, além de ser uma grande festa, o carnaval abre muitas possibilidades de geração de renda, pois, nesse período as agremiações contratam diversos serviços, como exemplo, o dos sapateiros, que no caso de Belém, confeccionam entre mil a duas mil sapatilhas para cada agremiação (são oito só no grupo especial), além de escolas e blocos de outras categorias. Outros serviços como das costureiras e bordadeiras na confecção de fantasias, dos artesãos na preparação das alegorias, dos serralheiros na construção das estruturas dessas alegorias, dos carpinteiros, dos pintores, entre outros profissionais que criam uma cadeia produtiva que se entrelaça, pois 
Na Economia do Carnaval, o produto carnavalesco por excelência - o desfile das escolas de samba, principalmente as do Grupo Especial possui um grande potencial de demanda sobre a indústria fornecedora de materiais típicos para a construção de carros alegóricos, tais como plástico, ferragens, isopor, tecidos, tintas etc., e para a confecção de fantasias e adereços, assim como é importante gerador de oportunidades de empregos, contratando serviços de diferentes especialidades, tais como modeladores, costureiras, marceneiros, coreógrafos, entre outros, para sua produção (PRESTES FILHO et al., 2011, p. 8-9).

A realidade do carnaval paraense não foge a essa demanda de materiais e de mão-de-obra especializados. As escolas de samba de Belém, ao se prepararem para o desfile, necessitam alugar um barracão ou galpão para a construção de suas alegorias, pois aqui, diferentemente do Rio de Janeiro, de São Paulo, de Macapá, de Manaus, entre outras capitais, não possui um sambódromo com uma estrutura de cidade do samba. Alguns serviços são imprescindíveis para que essa alegoria fique pronta para o dia do desfile. A base do carro alegórico é o chassi de caminhão, ônibus etc.

Os chassis passam por avaliação mecânica geral, revisão de pneus, para então irem para as mãos do serralheiro, que dará forma física aos traços do carnavalesco. Com a ferragem pronta, o serviço de marcenaria começa a ser executado para assoalhar o carro. Algumas partes do carro são fechadas com madeira, outras com papelão. Concomitante a isso as esculturas que comporão o cenário que será representado pelas alegorias, também estão sendo construídas. Algumas delas são articuladas e possuem movimentos. Os materiais usados para as esculturas são o isopor, a fibra de vidro, a papietagem, entre outros materiais.

Com o carro alegórico fechado inicia-se a decoração, a parte mais bonita, mais glamorosa, em que tecidos e os mais diversos materiais brilhantes, brilhosos e coloridos de várias texturas se misturam a espelhos, cristais, acrílico etc., para atenderem a criatividade e a inventividade do carnavalesco e de sua equipe. Para que esses materiais, depois de juntados, colados e pregados cada um no seu devido lugar obtenham um realce ainda maior, chega a vez da iluminação, e da escolha minuciosa dos destaques que subirão nessas alegorias, tudo isso é pensado e planejado junto com a criação da alegoria. Nas Figuras 1 e 2, as imagens do processo de construção do carro abre-alas e deste pronto que a BoleBole levou para a avenida no ano de 2013. 
Figura 1 - Carro abre-alas da Bole-Bole, ainda em fase de construção no barracão, para o carnaval 2013

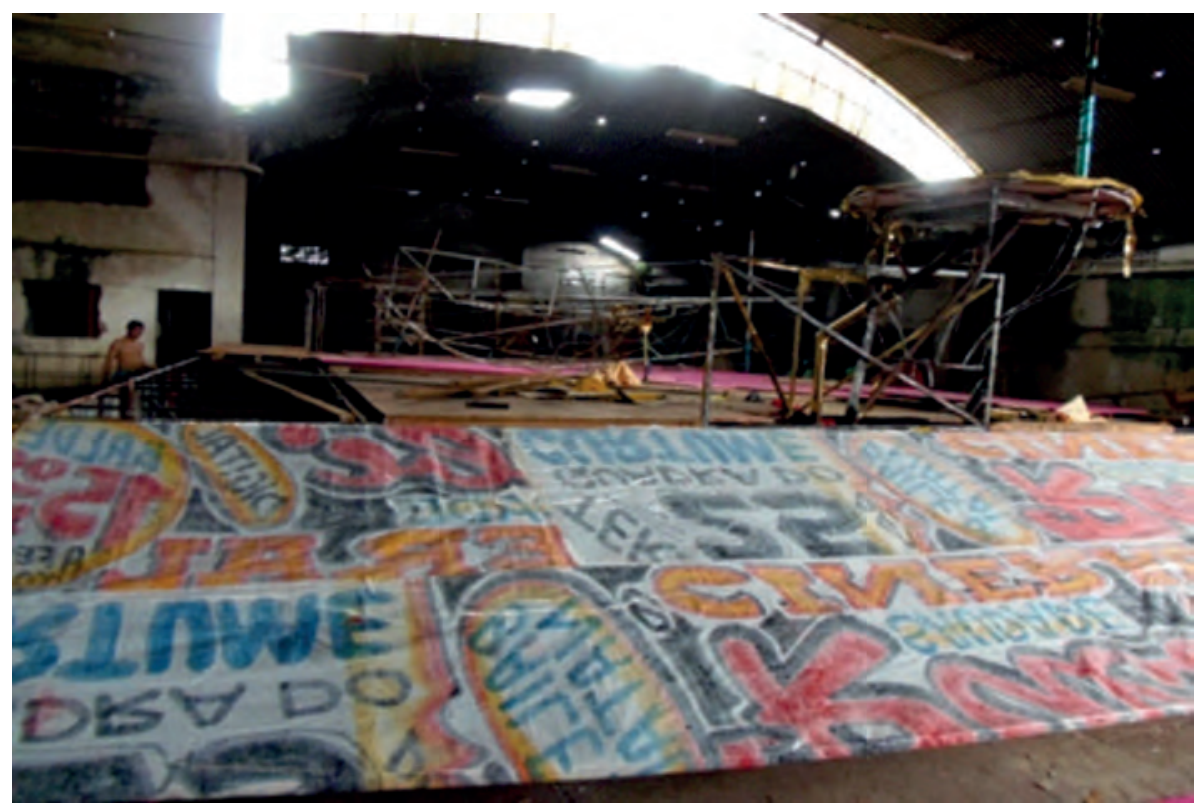

Fonte: Margarida Gordo

Figura 2 - Carro abre-alas da Bole-Bole, no desfile do carnaval de 2013

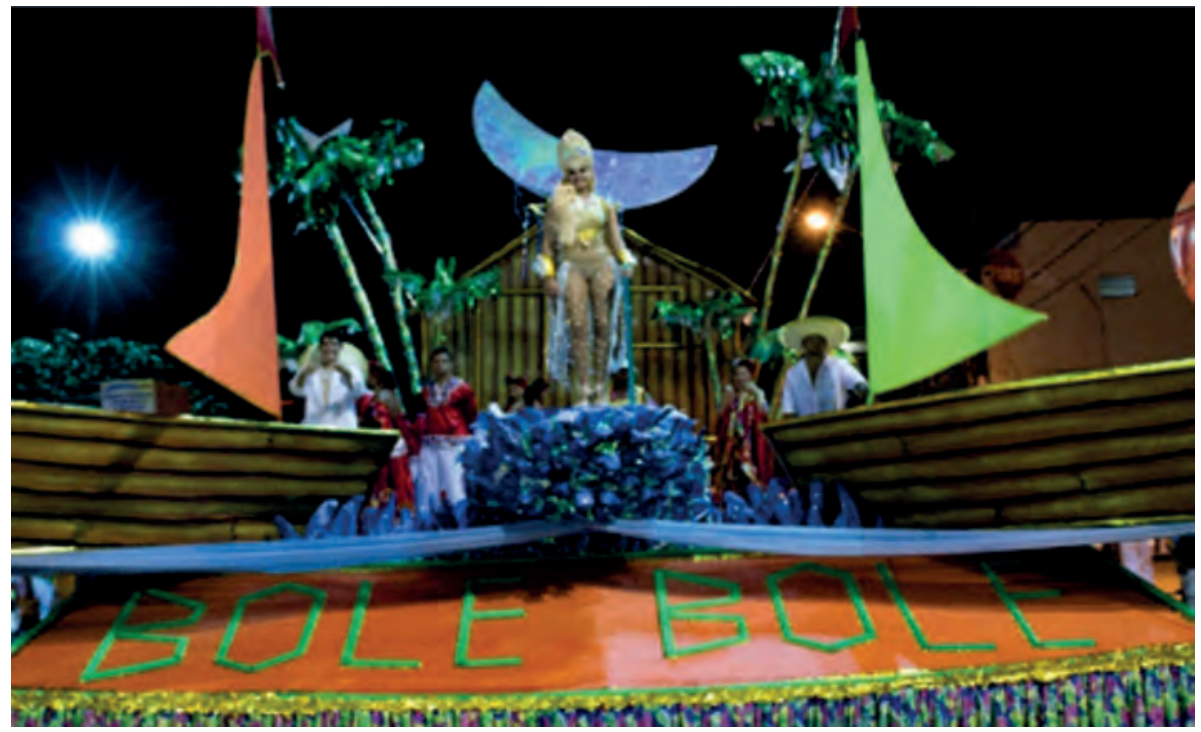

Fonte: George Souza 
Outro ponto importante para desenvolver o enredo de uma escola de samba são as fantasias das alas e de outros quesitos como comissão de frente, mestre sala e porta bandeira, porta estandarte (uma peculiaridade do carnaval de Belém), integrantes da bateria, ala das baianas etc.

Uma fantasia é composta por chapéu (item obrigatório), que pode ter sua base de papelão, EVA, arames, acetato, entre outros e de ser de várias formas; de resplendor (uma armação de ferro decorada que vai nas costas do brincante) é opcional, depende do que o carnavalesco pensou para aquela fantasia, bem como, da situação financeira da escola; a roupa propriamente dita, onde há uma mistura de tecidos com diversos materiais, como plumas, fitas, e outros artigos decorativos. Os pés deverão estar calçados, são sapatilhas, sapatos, botas etc. É importante registrar que cada ala deverá usar o mesmo tipo de fantasia, incluindo o sapato, com o intuito de manter a estética e a uniformidade, que será julgada sob a denominação de conjunto.

As fantasias dos quesitos como comissão de frente, mestre sala e porta bandeira e porta estandarte, por serem únicas, são confeccionadas com materiais mais sofisticados e caros do que as alas.

O ensaio é primordial para que a escola afine seus instrumentos juntamente com a vOz dos cantores, para que ambos desfilem em uma harmoniosa cadência, levando todos os brincantes a se envolverem na magia do carnaval. A comissão de frente, o mestre sala e a porta bandeira, o porta estandarte, as baianas, a bateria e demais componentes da escola também ensaiam durante o período que antecede o carnaval.

É importante salientar que a quadra da escola deverá estar equipada com som; deverá contratar os serviços de carro som, para os ensaios de rua, que proporcionarão aos componentes da escola, que ensaiem em locomoção com o intuito de simularem um desfile, organizando sua evolução, harmonia, conjunto etc. Há também, a confecção de camisas padronizadas para integrantes da "harmonia, chefes de ala e amigos" das escolas, além da alimentação dos trabalhadores do barracão.

A cadeia produtiva do carnaval envolve muita gente, profissionais de várias áreas e sua comunidade. Segundo Prestes Filho et al. (2009, p. 28), “a era romântica ficou para trás. Os barracões das escolas de samba funcionam hoje como linha de produção de uma moderna fábrica", por isso a necessidade de profissionais especializados. "Não há mais espaço para amadorismo e improviso" (PRESTES FILHO et al., 2009, p. 28). 
Abaixo nos Quadros de 1 a 5 há um demonstrativo - baseado na Escola de Samba Bole-Bole - das despesas necessárias para que as escolas participem do desfile oficial, tendo a seguinte sequência: alegorias, alas e quesitos, ensaios de quadra e de rua, pagamento de pessoal, entre outras. Não serão informados valores em reais, e sim em forma de percentual, que cada item representa no valor total que a escola arrecada.

Quadro 1 - Descrição e percentual de despesa com a construção e decoração das alegorias

\begin{tabular}{|l|l|}
\hline \multicolumn{1}{|c|}{ Item } & \\
\hline Serviços de serralheria & \\
\hline Serviços de mecânica dos carros & \\
\hline Serviços de borracharia & \\
\hline Serviços de marcenaria & \\
\hline Varas de ferro diversas & \\
\hline Madeiras diversas & \\
\hline Pregos diversos & \\
\hline Papelão & \\
\hline Tecidos (TNT, esponjado, cetim, lurex etc.) & \\
\hline Placas de acetato & \\
\hline Aluguel de barracão & \\
\hline
\end{tabular}

Fonte: Dados de Relatório Financeiro da Escola de Samba Bole-Bole (2014)

Quadro 2 - Descrição e percentual de despesa com a confecção de alas e quesitos

\begin{tabular}{|c|c|}
\hline Item & $\%$ \\
\hline $\begin{array}{l}\text { Tecidos (TNT, esponjado, cetim, lurex, tule, malha, rendas bordadas, } \\
\text { tecido paetê etc.) }\end{array}$ & \multirow{10}{*}{3} \\
\hline Materiais de aviamento (linhas, elásticos, velcro, paetês, fitas, gregas, etc.) & \\
\hline Materiais de decoração (paetês, fitas, gregas etc.) & \\
\hline Papelão & \\
\hline Placas de acetato & \\
\hline Plumas & \\
\hline Sapatilhas e sapatos & \\
\hline Maquiagem & \\
\hline Transporte & \\
\hline Aluguel de barracão para chapelaria & \\
\hline
\end{tabular}

Fonte: Dados de Relatório Financeiro da Escola de Samba Bole-Bole (2014) 
Quadro 3 - Descrição e percentual de despesas com ensaios de quadra e de rua

\begin{tabular}{|l|c|}
\hline \multicolumn{1}{|c|}{ Item } & $\%$ \\
\cline { 1 - 1 } Som & \multirow{2}{*}{5} \\
\cline { 1 - 1 } Carro Som & \\
\hline Banner e Panfletos com a letra do samba
\end{tabular}

Fonte: Dados de Relatório Financeiro da Escola de Samba Bole-Bole (2014)

Quadro 4 - Descrição de despesa e percentual de pagamento de pessoal

\begin{tabular}{|l|l|}
\hline \multicolumn{1}{|c|}{ Item } & \\
\cline { 1 - 1 } Carnavalesco & \\
\cline { 1 - 1 } Cantores & \\
\hline Músicos & \\
\hline Serralheiros & \\
\hline Artesãos & \\
\hline Costureiras & \\
\hline Sapateiros & \\
\hline Empurradores & \\
\hline Seguranças & \\
\hline
\end{tabular}

Fonte: Dados de Relatório Financeiro da Escola de Samba Bole-Bole (2014)

Quadro 5 - Descrição de despesas diversas com seu respectivo percentual

\begin{tabular}{|l|c|}
\multicolumn{1}{|c|}{ Item } & $\%$ \\
\cline { 1 - 1 } Camisas (diretoria, harmonia, chefes de ala, empurradores e segurança) & \multirow{2}{*}{5} \\
\cline { 1 - 1 } Alimentação do pessoal dos barracões & 5 \\
\hline Despesas diversas &
\end{tabular}

Fonte: Dados de Relatório Financeiro da Escola de Samba Bole-Bole (2014)

Em Belém o Departamento Intersindical de Estatísticas e Estudos Socioeconômicos (DIEESE) não contabiliza a cadeia produtiva que se encerra em torno do carnaval. Tal atitude acaba por encobrir uma realidade muito presente nas escolas de samba, pois, mesmo por um período curto, há um aquecimento no comércio local, bem como costureiras, sapateiros, artesãos etc., conseguem um trabalho em troca de pagamento pelos serviços prestados.

"Eficiência e eficácia, rentabilidade e adequação, receita e custos, controle e qualidade são os atributos do desfile que agora devem prevalecer, para atender ao deslumbramento frequente de turistas" (PRESTES FILHO et al., 2009, p. 2829), bem como para atender aos interesses públicos dos órgãos arrecadadores de 
impostos, dos empresários que lucram com a prestação de serviços nessa época e da própria escola que precisa manter-se entre os primeiros lugares, a fim de resguardar seu espaço.

Como demonstrado até aqui, é possível visualizar a imensa complexidade para que uma escola de samba consiga chegar pronta e completa na avenida. Para isso ela passa por vários processos, os quais iniciam com a ideia e com o nascimento do enredo; depois vem samba; muito ensaio (comissão de frente, mestre-sala e porta-bandeira, porta-estandarte, bateria, baianas etc.); muito papel riscado até que os desenhos das fantasias e das alegorias estejam prontos; aí vem os protótipos; ferragens, tecidos diversos e outros materiais, para que então uma escola desfile na avenida do samba. Por trás de tudo isso, tem uma grande equipe trabalhando, contratação de som de quadra e de rua, materiais de reposição da bateria, enfim uma cadeia humana e mercadológica sendo fomentada a todo momento.

\section{ESCOLA DE SAMBA: COMUNIDADE E IDENTIDADE}

No Brasil, quando se pensa em carnaval, pensa-se imediatamente no longo período de feriado, em muitos bailes, desfiles oficiais, micaretas, mulheres bonitas com o mínimo de vestimenta, homens não menos atraentes e desnudos, ou seja, uma festa com todos os ingredientes de ócio e paganismo (MOTTA, 2003). Talvez, por isso, o carnaval seja considerado apenas uma festa, e uma festa mal vista por muita gente. Mas o que tem de errado em ser uma festa?

O carnaval vai além de seu ingrediente festivo, principalmente quando se trata de escola de samba - objeto deste estudo - a qual para desfilar no carnaval, como assinala Tramonte (2007), desenvolve no decorrer de um ano, um trabalho que congrega a comunidade em seu entorno, abrindo espaço para geração de emprego e renda, oficinas de arte, principalmente nas áreas da dança, música e artes plásticas, entre outras ações que se traduzem em benefício para aquela comunidade.

O sentido de comunidade neste texto extrapola os definidos pelos dicionários, como em Ferreira (2008, p. 252) que a define como "o corpo social; a sociedade". O sentido aqui impresso é de um superorganismo, como assinala Manzini (2012), no qual a comunidade se sente dona daquele universo, protegendo e protegida por ele. Ainda segundo essa autora, uma das características da comunidade ou desse superorganismo, é resistir ao que vem de fora dela, ao que lhe é estranho. 
Carneiro (2011), em pesquisa realizada na Escola de Samba da Mangueira, destaca a delimitada fronteira entre a comunidade e a sociedade, entre 0 nós e 0 eles, ou seja, entre as pessoas da comunidade com as de fora, denominadas de sociedade. Ressalta ainda a autora que para não perder força, a comunidade não se isenta em se autoafirmar como patrimônio cultural, demarcando seu lugar e sua importância para a perpetuação de sua escola de samba.

Desta forma, a relação entre comunidade e sociedade, mediada pela escola de samba, mais especificamente pelo mundo do samba, como assinala Tramonte (2007), se estabelece por meio de alguns fenômenos, os quais só poderão ser compreendidos se houver o entendimento de que sua ocorrência não se dá isoladamente ou desconectada, há uma inter-relação formando uma rede contraditória, a qual imbrica-se mutuamente. Tramonte (2007, s.p.) ressalta que a "configuração do Mundo do Samba, bem como o papel mediador nos processos pedagógicos cumpridos pela escola de samba, delineará suas características conforme o momento histórico e o contexto social em que se inserem”.

Para Tramonte (2007), há um aspecto pedagógico bem delineado que busca estabelecer essa convivência e consolidar a base comunitária como garantia da manutenção das raízes e perpetuação da agremiação. Aprender a tocar um instrumento, dançar, representar, cantar, compor, desenhar, cortar, costurar, colar, transformar, criar, sonhar, se relacionar, se entregar para viver e aprender, são processos vivos na escola de samba e que congregam as pessoas fortalecendo os laços identitários delas com a escola de samba a que pertencem. E isso tudo é muito vivo na Bole-Bole.

Ao ler e analisar os enredos e sambas-enredo da Bole-Bole, verifica-se uma preocupação desta escola em construir uma identidade com o seu bairro. $\mathrm{O}$ Guamá com sua diversidade, suas peculiaridades, seus problemas, suas inúmeras possibilidades e movimentos de cultura popular etc., é frequentemente cantado no carnaval da escola, ou seja, suas características viram enredo e samba-enredo (GORDO, 2015).

Abaixo segue o samba-enredo de 1999 composto por Dio, Magé e Ademir do Cavaco - foi a única vez que houve concurso de samba na Bole-Bole, pois esta escola possui seu compositor, Vetinho (também compositor dos três primeiros sambas da escola Arco-Íris), que desde sua fundação compôs todos os sambas da escola, com exceção deste. Algumas vezes estabelecendo parcerias - enredo idealizado por Vetinho A Fantasia de um Guamá Felize e interpretado por Ademar Carneiro, que ilustra o objetivo desta escola em seus sambas-enredo 
Um sonho bonito vivi, na fantasia desse carnaval. Onde o Barão de Igarapé-Miri, num Guamá em decadência, reúne os gênios num conselho especial, pra satisfação geral. E assim na foz do Tucunduba se fez o nosso enredo genial. Saúde e educação com a conservação da cultura regional. Trabalho e lazer, criança na escola. Morada pra todos, transporte na hora. Sem SPC, sem delegacia, o nosso Guamá feliz existia. E sempre amanhecia com alegria. No fim da tarde a poesia. No pôr do sol, a namorada. Vem a noite, a boemia. Ao luar, trovadores nas calçadas. No barracão o BoleBole se prepara, e o sonho vira alegoria. Salve o Barão do Rio Guamá, e mãe Amelinha, o terreiro secular. Sonhar é viver, e no Guamá isso é normal! Na quarta-feira vem a realidade, aí eu penso em outro carnaval.

Esse enredo tinha como ponto de partida o sonho dos guamaenses. Nesse sonho, o Barão de Igarapé-Miri - nome de uma das principais avenidas existentes no bairro do Guamá - reúne as mentes mais geniais, que estão se desenvolvendo na Universidade Federal do Pará (UFPA), para desenvolver pesquisas em prol de mudanças propositivas na área da educação, saúde, transporte, moradia, urbanização, trabalho, lazer, mas sem se apartar do romantismo vivido em épocas passadas, e sem esquecer de pedir as bênçãos no terreiro de umbanda secular localizado na mesma rua que a Bole-Bole.

É também recorrente o apelo para que a UFPA, localizada neste bairro, às margens do rio Guamá, volte sua atenção por meio de ações, nas mais diversificadas áreas, para minimizar problemas relacionados à educação, saúde, meio ambiente, urbanização entre outros, por meio de suas tecnologias. A exposição dos problemas e das virtudes do bairro é uma tentativa de atrair a atenção da classe política e empresarial. Os problemas, para tentarem ser resolvidos e as virtudes, para que consigam incentivo, fomento e políticas públicas para se expandirem.

Como no desfile de 2001, com o enredo O Sol nasce no Guamá, numa homenagem ao radiante astro que rebenta todas as manhãs, despontando seus primeiros raios no Guamá, por ser o bairro que se situa mais a leste na cidade de Belém, com samba de Vetinho e interpretado por Ademar Carneiro

Na beira do rio, do rio Guamá. É a morada do sol nascente! É o ninho do saber, é o oriente. Que Bole-Bole o coração de nossa gente! É hora de realizar um sonho tão antigo: vencer os velhos inimigos, miséria, poluição a degradar. Ciências, tecnologias sem burocracia. É o anseio da comunidade. Ver a Universidade em projetos de ação, em busca de uma solução. Fazer o Tucunduba desaguar feliz, e resgatando a cultura da raiz. Ainda queremos ver: o fim da guerra urbana, dessa luta desumana e o lixo reciclar. A arte-consciência, a vida, pode transformar! E o samba em nova cadência: no sirimbangu-ê, no carimboi-bumbá. O sol já vai nascer, vem bolebolear! É pai d'égua o pop brega no Guamá. 
Nesse enredo, crítico e apelativo, a Bole-Bole volta a evocar a UFPA para cuidar do bairro do Guamá - desburocratizando suas ações; tornando sua tecnologia a serviço dos guamaenses, como a recuperação do rio Tucunduba que passa por dentro da universidade e está com alto índice de poluição etc. contribuindo para que seus moradores tenham acesso à educação, aliando a arte a essas ações.

Mas o objetivo principal desses sambas é a construção de uma identidade com o bairro, levar informação e aguçar a criticidade dos moradores do Guamá. Esse despertar proposto pela Bole-Bole, tanto da universidade quanto da classe política e da comunidade é mediado pelo samba, acompanhado pela bateria e cantado com vigor por sua comunidade, pois reconhecer-se em determinado lugar está diretamente ligado com sua identidade.

Outra função dos sambas-enredo da Bole-Bole (frutos de pesquisas de carnavalescos e compositores) tem sido de informar aos moradores mais jovens e de lembrar aos mais antigos, que o Guamá é o bairro da cidade de Belém com uma das maiores diversidades de manifestações de cultura popular paraense: boibumbá, pássaro junino, quadrilhas roceiras, grupos musicais de vários gêneros, procissões e festas religiosas, terreiros de umbanda, entre outros.

Isto pode ser comprovado neste samba composto por Vetinho em 2002 que homenageou o grupo musical Arraial do Pavulagem com o enredo A pavulagem do meu povo, promovendo uma mistura rítmica, entre o batuque do boi com o samba e outros ritmos regionais. O samba interpretado por Ademar Carneiro era assim,

O Arraial do Pavulagem reuniu, nosso folclore num banzeiro cultural. Mostrando a festa cabocla pra todo o Brasil! Fez nosso jeito de brincar o carnaval. Bole-Bole num tambor de couro! Xequerê num maracá de cuia! Reco-reco de bambú, urucum na cara. Ficou pai d'égua esse banzeiro Paraoara! Será que é retumbão, ou é bangu-ê, carimboi na rua, ou siriáa, ou siriáa! Que esse samba de cacete tem magia. No arraial que é do sol, no arraial que é da lua! Diz a tacacazeira: menino, é lindo meu Guamá nessa folia! Veja o Arraial chegou e me arrastou! Venha, esse banzeiro é um Paraoá de amor! Dança Boi Tinga, bicho folharal. Axé? axi, meu cheiro é peixe regional! Meu rio é Rui, é Tiritó, Lucindo, Baldez, Waldemar-açu! Tem boto no Sairé, no Mexilhão do Icatu! Quem é jarana vai morar no sul. Hei, bole-boi, bole-boi, bole-boi, bole-boi, bole-boi.

O Arraial do Pavulagem é mais que um grupo musical, ele agrega valores da cultura paraense, além de ter iniciado sua trajetória musical e de oficinas na sede do bloco Bole-Bole na década de 1990, junto à comunidade da Pedreirinha, mediada por Vetinho e Nazareno Silva, como assinala Vieira (2014, p. 2 e 3) 
A força criada a partir da mobilização da comunidade do Guamá foi o elemento fundamental para o nascimento e o desenvolvimento de outras iniciativas culturais no Bole-Bole e no bairro do Guamá. Assim apareceu o Arraial do Pavulagem no terreiro do Bole-Bole e seu Malhadinho, que veio somar esforços aos empreendimentos de Vetinho e Nazo Silva e outros colaboradores. A sua presença no Bole Bole levou a uma maior visibilidade do que se fazia nesta agremiação. Acho que até influenciou na forma do Pavulagem se apresentar, com crianças. Fortaleceu o elo entre o Boi Pavulagem e o Malhadinho, recém resgatado. Era lindo ver a relação de um boi maduro com um boi criança!

Fica nítido nas palavras de Vieira (2014) o compromisso da Bole-Bole com a cultura popular e com práticas educativas envolvendo a juventude e a comunidade guamaense. Esse envolvimento sensibiliza e atrai artistas, intelectuais, acadêmicos e pesquisadores que transitam, mesmo que temporariamente, trocando saberes, experiências e conhecimentos com os guamaenses.

A Bole-Bole tem uma sede que é um dos raros espaços existentes no bairro, onde comporta reunião de entidades, instituições, partidos políticos etc.; comando médico; vacinação (de gente e de animais); festas religiosas, profanas e escolares, dentre tantas outras atividades promovidas pela própria escola ou que seja de interesse de sua comunidade.

Assinala Poubel (2012, p. 12) que "os moradores de uma mesma localidade têm na escola de samba uma referência para a construção de identidades sociais, estabelecendo discursos e práticas em comum". Revela ainda Poubel (2012, p. 12) que "o fato de pertencer a uma escola de samba de determinado bairro cria relações entre as pessoas, atuando na construção de identidades e representações sociais que orientam as práticas dos moradores dessas localidades". Essa identidade e esse vínculo estabelecido com a escola de samba cria uma relação de pertencimento.

\section{CONCLUSÃO}

Quando esforços foram unidos para compor este artigo, a missão foi fazer um registro sobre o mercado carnavalesco em Belém tendo como referência os dados financeiros da Escola de Samba Bole-Bole. Porém, não dá para reduzir essa escola às questões financeiras, principalmente pela forte identidade e elo criados com sua comunidade, com o bairro do Guamá, com a passagem Pedreirinha, enfim, com todo seu entorno. Por isso, economia, comunidade e identidade passaram a dialogar na construção deste artigo. 
Acredita-se que não cabe mais imitar o espetáculo promovido pelas escolas do Rio de Janeiro, não tem recursos para isso, há que se repensar esse modelo e retomar o compromisso por parte de todos os envolvidos com o carnaval de Belém - poder público em todas as esferas, empresas, mídia e gestores das escolas de samba - em prol de seu soerguimento para que as agremiações carnavalescas venham se fortalecer, se tornarem autossustentáveis e continuarem gerando mais empregos e renda, dentro da cadeia produtiva do carnaval.

Somado a isso tudo, as escolas necessitam contar com a viabilidade de políticas públicas por meio de projetos sociais que tragam mais recursos para que consigam se manter o ano inteiro interagindo com suas comunidades, melhorando a qualidade de vida dessa população, além de se aprontarem para o desfile oficial de carnaval.

É importante ressaltar que uma escola de samba não se resume ao dia do desfile oficial no carnaval, a avenida é palco para a evolução de ideias colocadas em prática por pesquisadores, carnavalescos, ferreiros, carpinteiros, costureiros, coreógrafos, ritmistas, compositores etc., que desenvolvem tudo isso de forma artística, ordenada, metódica e didática durante o ano todo.

\section{REFERÊNCIAS}

BAKHTIN, M. A cultura popular na idade média e no renascimento: o contexto de François Rabelais. São Paulo: HUCITEC; Editora da Universidade de Brasília, 1987.

CARNEIRO, A. Uma antropologia nativa da família verde-e-rosa ou conceito nativo. Por que ver rizoma onde nos mostram uma mangueira frondosa? Cadernos de Campo, São Paulo, n. 20, p. 15-31, 2011.

DA MATTA, R. Universo do carnaval: imagens e reflexões. Rio de Janeiro: Pinakotheke, 1981.

DAWSEY, J. C. O teatro dos "boias-frias": repensando a antropologia da performance. Horizontes Antropológicos, Porto Alegre, a. 11, n. 24, p. 15-34, jul./dez. 2005.

DIÁRIO DO PARÁ. Estelionato é a mais nova jogada de Mário Couto. Domingo, 03.03.2013, 08:13:48 - Atualizado em 03.03.2013, 08:23:10. Disponível em: http://www.diarioonline.com.br/noticia-237847-estelionato-e-a-mais-novajogada-de-mario-couto.html. Acesso em: 22 ago. 2013. 
DIAS JUNIOR, J. E. S. Cultura popular no Guamá: um estudo sobre o boibumbá e outras práticas culturais em um bairro da periferia de Belém. 2009. $161 \mathrm{f}$. Dissertação (Mestrado em História) - Instituto de Filosofia e Ciências Humanas, Universidade Federal do Pará, Belém, 2009.

FERrEIRA, A. B. de H. Mini Aurélio: o dicionário da língua portuguesa. 7. ed. Curitiba: Editora Positivo, 2008.

FERREIRA, C. P. Sociabilidade e espaço público: experiências de ações culturais educativas na passagem Pedreirinha do Guamá - Belém-Pará. 2012. Dissertação (Mestrado em Ciências Sociais - Antropologia) - Instituto de Filosofia e Ciências Humanas, Universidade Federal do Pará, Belém, 2012.

GALVÃO, W. N. Ao som do samba: uma leitura do carnaval carioca. São Paulo: Fundação Perseu Abramo, 2009.

GONÇALVES, R. S. Os ranchos carnavalescos e o prestígio das ruas: territorialidades e sociabilidades no carnaval carioca da primeira metade do século XX. Textos escolhidos de cultura e arte populares. Rio de Janeiro, v. 3, n. 1, p. 71-80, 2006.

GORDO, M. E. S. C. O carnaval é o quintal do amanhã: saberes e práticas educativas na escola de samba Bole-Bole em Belém do Pará. 2015. Tese. (Doutorado em Educação) - Universidade Estadual de Campinas, Campinas-SP, 2015.

MANZINI, Yaskara Donizeti. Pra tudo se acabar na quarta-feira: aproximações, diálogos e estranhamentos entre carnaval e teatro nas performances da comissão de frente. 2012. 234f. Tese (Doutorado em Artes) - Universidade Estadual de Campinas, Campinas-SP, 2012.

MARQUEIRO, P. A estatização das escolas de samba. Disponível em: http://moglobo.globo.com/integra.asp?txtUrl=/opiniao/mat/2010/02/12/aestatizacao-das-escolas-de-samba-915851511.asp. Acesso em: 10 jul. 2011.

MOTTA, J. F. A cultura do samba nas gaiolas da educação. 2003. 204f. Tese (Doutorado em Educação) - Universidade Federal do Rio de Janeiro, Rio de Janeiro, 2003.

OLIVEIRA, A. Carnaval paraense. Belém: SECULT, 2006.

PALHETA, C.; RODRIGUES, C. I. Do enredo ao desfile, a campeã do carnaval.

Revista Ensaio Geral, Belém, v. 2, n. 4, p. 47-56, ago./dez. 2010. 
POUBEL, M. S. O bairro e a escola de samba: sociabilidade e pertencimento em Vila Isabel (RJ). 2012. 104f. Dissertação (Mestrado em Sociologia e Antropologia) - Instituto de Filosofia e Ciências Sociais, Universidade Federal do Rio de Janeiro, Rio de Janeiro, 2012.

PRESTES FILHO, L. C.; et al. Cadeia produtiva da economia do carnaval. Disponível em: http://www.gestaocultural.org.br/livrosonline.asp?page=cadeiaprodutiva. Acesso em: 06 ago. 2011.

RELATÓRIO DA ESCOLA DE SAMBA BOLE-BOLE. Dados financeiros. Belém: Acervos da Escola, 2014.

TRAMONTE, C. Aspectos educativos do carnaval no Brasil: a pedagogia das escolas de samba. In: Os Urbanistas - Revista de Antropologia Urbana, a. 4, v. 4, n. 6, 2007. Disponível em: http://www.osurbanitas.org/osurbanitas6/ Tramonte2007-c.html. Acesso em: 10 mar. 2014.

TRAMONTE, C. O samba conquista passagem: as estratégias e a ação educativa das escolas de samba. Petrópolis-RJ: Vozes, 2001.

VIEIRA, I. Declaração: vivências na Associação Carnavalesca Bole-Bole na década de 1990. 2014. (Documento escrito em 2014 e publicado na tese de doutorado de GORDO, M. E. S. C, 2015, p. 183-1850) 